\title{
Farklı pH Çözeltileri ve Donma Çözülmenin Travertenlerin Fiziko- Mekanik Özelliklerine Birlikte Etkisi
}

\author{
Engin Özdemir ${ }^{*}$ \\ 1* İnönü Üniversitesi, Mühendislik Fakültesi, Maden Mühendisliği Bölümü, Malatya, Türkiye, (ORCID: 0000-0002-6043-0403), ozdemir.engin@inonu.edu.tr
}

(International Conference on Design, Research and Development (RDCONF) 2021 - 15-18 December 2021)

(DOI: 10.31590/ejosat.1039246)

ATIF/REFERENCE: Ozdemir, E. (2021). Farklı pH Çözeltileri ve Donma Çözülmenin Travertenlerin Fiziko-Mekanik Özelliklerine Birlikte Etkisi. Avrupa Bilim ve Teknoloji Dergisi, (32), 1-6.

\begin{abstract}
$\ddot{\mathbf{O z}}$
Traverten, blok verme, çeşitli desenlere sahip olma ve kolay işlenebilir olmasından dolayı inşaat malzemesi olarak oldukça yaygın bir kullanım alınana sahiptir. Fakat porozite açısından diğer doğal taşlara nazaran daha boşluklu yapılara sahip olması en büyük dezavantajıdır. Bu durum, travertenlerin dış mekânlarda kullanım alanlarını oldukça kısıtlamaktadır. Özellikle, çok yağış alan ve donmaçözünme olaylarının fazla göründüğü ortamlarda bu tür doğal taşların kullanımı önerilmemektedir. Birçok araştırmacı donma çözünmenin travertenlere etkisini araştırırken su ile doygun hale getirmiş̧tir ve suyun asidik-bazik özelliklerini incelememişlerdir. Bu çalışmada, donma çözünmenin farklı pH çözeltilerine (2.0, 7.0 ve 12.0) maruz bırakılarak birlikte etkisi ele alınmıştır. Bu amaçla, Malatya kırmızı traverten ve Erzurum traverten üç farklı çözelti kullanılarak 20 kez donma-çözünmeye maruz bırakıldı ve her 5 döngü sonunda tek eksenli basınç dayanımı, P dalga hızı ve Schmidt çekici sertlik değerleri tayin edildi. Çalışma sonucunda, pH değeri azaldıkça ve donma çözünme döngü sayıları arttıkça travertenlerin tek eksenli basınç, P dalga hızı ve Schmidt çekici sertliğindeki düşüş artmiştır.
\end{abstract}

\section{The Combined Effect of Different pH Solutions and Freeze-Thaw on Physico-Mechanical Properties of Travertines}

\begin{abstract}
Travertine is widely used as a construction material due to gives blocks, various patterns and easy to process. However, its biggest disadvantage is that it has a more porous structure than other natural stones. This situation restricts the outdoor usage areas of travertines. Especially, in environments that receive heavy rainfall and freeze-thaw events, the use of such natural stones is not recommended. Many researchers, while investigating the effect of freeze-thaw on travertines, saturated with water and did not determine acidic-basic properties of water. In this study, combined effect of freeze-thaw by exposure to different $\mathrm{pH}(2.0,7.0$ and 12.0$)$ solutions is investigated. For this purpose, Malatya red travertine and Erzurum travertine were exposed to freeze-thaw 20 times using three different solutions and at the end of every 5 cycles, uniaxial compressive strength, $\mathrm{P}$ wave velocity and Schmidt hammer hardness values were determined. As a result of the study, the decrease in uniaxial compressive strenght, $\mathrm{P}$ wave velocity and Schmidt hammer hardness of travertines increased as $\mathrm{pH}$ value decreased and freeze-thaw cycle numbers increased.
\end{abstract}

Keywords: Natural stones, $\mathrm{P}$ wave velocity, $\mathrm{pH}$, Uniaxial compressive strength, Travertine

\footnotetext{
*Sorumlu Yazar: ozdemir.engin@inonu.edu.tr
} 


\section{Giriş}

Doğal taşlar, tarih boyunca farklı medeniyetler tarafindan estetik görünümü, şekil verilebilirliği, doğal desenleri gibi avantajlarından dolayı sanat, yapı ve dekorasyon çalışmalarında yaygın olarak tercih edilmiştir (Vincenzo vd. 2018; Swathy, 2020). Artan nüfusa paralel olarak inşaat sektöründe yap1 malzemesi olarak (zemin kaplama, dış kaplama, yığma duvar vb.) doğal taş kullanımına olan talep her geçen gün artmaktadır. Doğal taşlar doğada mevcut olarak oluşan blok veren, plaka haline dönüşebilen, kesilebilen ve cila tutması nedeniyle gerçek mermerlerin $\left(\mathrm{CaCO}_{3}\right.$ içerikli metamorfik yapılı) yerine kullanımı cazip hale gelmiştir (Weddfelt vd. 2017; Aghababaei vd. 2019).

Doğal taşlar, farklı çevre koşulları nedeniyle fiziksel, mekanik ve kimyasal değişimlere uğrarlar ve başlangıçtaki dayanım özelliklerini zamanla kaybederler. Doğal taşların kullanım alanları belirlenirken sadece doğal ortamdaki fizikomekanik özellikleri değil, aynı zamanda kullanım ortamına bağlı olarak maruz kalacağ 1 çevresel faktörler de belirlenmesi gerekmektedir. Bazı araştırmacılar, sıcaklık (Hajpál, 2002; Koca vd., 2006; Lam dos Santos vd. 2011; Ozguven ve Özçelik, 2014), donma-çözülme (Freire-Lista vd. 2015; Jamshidi vd. 2016; Sarıcı ve Özdemir, 2018; Luo vd. 2021), tuz kristallenmesi (Yavuz ve Topal, 2007; Erdoğan ve Özvan, 2015; Barone vd., 2015; Sarıc1 vd. 2018), 1slanma-kuruma (Hale ve Shakoor, 2003; Oguchi ve Yuasa, 2010; Akin ve Ozsan, 2011; Deng, 2012), asidik-bazik ortama karşı direnç (Sharma vd., 2007; Kryza, 2009; Müller, 2018; Taghipour, vd. 2015) gibi çevresel faktörlerin doğal taşlar üzerine etkisini araştırmışlardır.

Fener ve İnce (2015), inşaat sektöründe kullanılan andezitik kayaçlar (Sille-Konya/Türkiye) üzerinde donma-çözülme döngüsünün etkilerinin etkisini belirlemek için laboratuvar ortamında deneysel çalışma gerçekleştirmişlerdir. Donma çözülme döngülerine bağlı olarak, gözeneklilik, tek eksenli basınç dayanımı, nokta yük dayanımı, dolaylı yoldan çekme dayanımı, Böhme aşınma kaybı ve ultrasonik dalga hızındaki değişiklikleri hem deneysel hem de istatistiksel olarak değerlendirmişlerdir. Gökçe vd. (2016), Anadolu'nun en eski insan yerleşimlerinden biri olan Konya'nın tarihi yapılarda yaygın olarak kullanılan Gödene travertenlerinin donma-çözülmeye karşın fiziko-mekanik özelliklerindeki değişimleri incelemişlerdir. $\mathrm{Bu}$ amaçla, donmaçözülme döngü sayısına bağlı olarak Gödene traverteninin porozite, tek eksenli basınç dayanımı, nokta yük dayanımı, dolaylı yoldan çekme dayanımı, Böhme aşınma kaybı ve P dalga hızı değerlerindeki değişimleri hem deneysel hem de istatistiksel olarak incelemişlerdir. Sarıcı ve Özdemir (2018), Türkiye'nin farklı lokasyonlarından alınan sedimanter kökenli bazı kayaçların fiziksel ve mekanik özellikleri üzerinde donma-çözülme döngülerinin etkisini belirlemek için numunelere $30 \mathrm{kez}$ donmaçözülme döngüsüne tabi tutmuşlar ve her beş döngüden sonra gözeneklilik, nokta yük dayanımı, Schmidt sertliği ve ağırlık kaybı değerlerini belirlemişlerdir. Donma-çözülme döngüsünün sayısı artıkça, nokta yük dayanımı, Schmidt çekici sertliği ve ağırlık değerlerinde azalmalar meydana geldiğini ve numunelerin gözenekliliğinde ise artış olduğunu ifade etmişlerdir. Amirkiyaei vd. (2020), İran'daki çeşitli ocaklardan çıkarılan 22 adet doğal taşın ( 3 çeşit kalker, 12 çeşit traverten ve 7 çeşit mermer olmak üzere) donma-çözülme döngülerine bağlı olarak P-dalga hızındaki değişimleri belirlemek için ampirik bir denklem geliştirmişlerdir. Bu ampirik denklemi donma-çözülmeye maruz kalan kayaçların bozulma miktarlarını değerlendirmek için kullanılabilirliğini vurgulamışlardır.

Yapılan çalışmalar incelendiğinde donma-çözülme döngülerinde saf su kullanılmaktadır. Suyun asidik veya bazik olması durumu göz ardı edilmiştir. Bu çalışma, iki farklı lokasyondan alınan travertenin farklı $\mathrm{pH}$ çözeltilerine ve donmaçözülme döngüsünün birlikte etkisini incelmiştir. Bu amaçla, üç farklı pH çözeltisi $(2.0,7.0$ ve 12.0) hazırlanmış, $20 \mathrm{kez}$ donma çözülme işlemine tabi tutulmuştur. Her 5 döngü sonunda ise $\mathrm{P}$ dalga hızı, Schmidt çekici sertliği ve tek eksenli basınç dayanımları tayin edilmiştir.

\section{Materyal ve Metot}

\subsection{Materyal}

Bu çalışmada, Malatya ve Erzurum illerinden temin edilen iki farklı travertenin fiziko-mekanik özelliklerini tayin etmek için yaklaşık 40x40x50 cm ebatlarına sahip blok numuneler laboratuvar ortamına taşınmıştır. Nakliye, taşıma ve örnek alım işlemlerinde deney sonucu etkileyebilecek her türlü darbe, çarpma, düşme vb. unsurlar oluşmaması için gerekli tedbirler alınarak çalışılmıştır. Her bir kayaç türünden, karot alma makinesi ve karot ucu kesme düzletme makinesi yardımıyla L/D (boy/çap) oranı yaklaşık 2.5-3.0 olan 60 adet olmak üzere toplamda 120 numune deneysel çalışmalar için hazırlanmıştır. Deneysel çalışmada elde edilen bazı görüntüler Şekil 1'de verilmiştir.

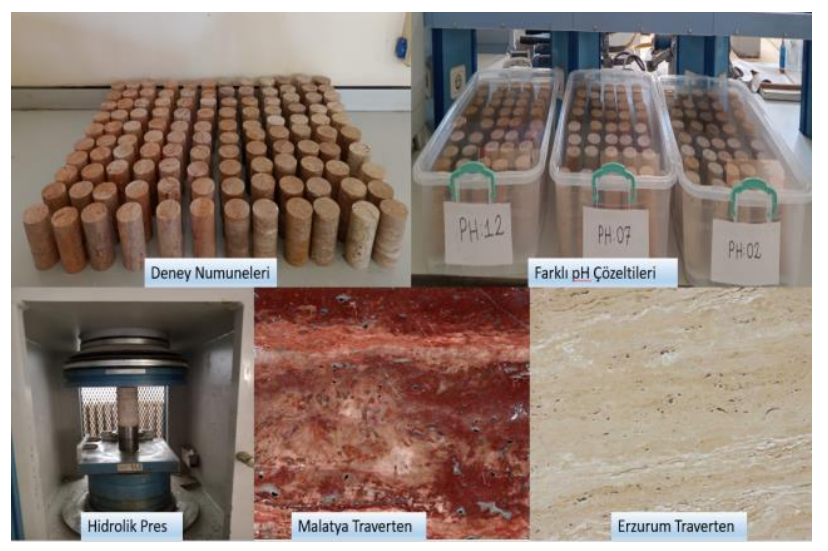

Şekil 1. Deneysel çalışmada kullanılan numuneler ile ilgili bazı görüntüler

\subsection{Yöntem}

\subsubsection{Donma-Çözülme Test}

İklimsel ve mevsimsel ani değişimler doğal taşların fizikomekanik özelliklerinde bazı olumsuz etkilere neden olmaktadır. $\mathrm{Bu}$ etki veya döngü sayısına bağlı olarak kayaçlar kısmen veya tamamen parçalanarak başlangıçtaki dayanım veya dayanıklılığını kaybedebilmektedir. Kayacın kılcal, mikro ya da makro gözeneklerine suyun girmesi ve sıcaklığın sıfırın altına düşmesi durumunda su sıvı halden buz hale geçmektedir. Su katı hale geçtiğinde ise mevcut hacminden yaklaşık \%9 oranda artmasından kaynaklı olarak kayacın gözeneklerine ve süreksizliklerine basınç uygulamaktadır. Böylesi donma-çözülme döngülerine maruz kalan kayaçlarda fiziksel ayrışma gözlemlenmektedir. Ayrıca bu çalışmada, yalnız saf suyun değil aynı zamanda asidik ve bazik çözeltilerin $\left(\% 5 \mathrm{H}_{2} \mathrm{SO}_{4}\right.$ ve $\mathrm{Na}_{2} \mathrm{SO}_{4}$ çözeltileri) donma çözülme üzerine etkisi ele alınmıştır. $\mathrm{Bu}$ amaçla çalışmada kullanılan sıvı üç farklı pH (2.0, 7.0 ve 12.0) kullanılarak gerçekleştirilmiştir. Doğal taşlar döngüsel işleme 
başlamadan önce ilk olarak, farklı pH çözeltilerinde 48 saat süre boyunca çözelti içerisinde bekletilerek doygun hale getirilmiştir. Daha sonra 18 saat süre Microtest MDC markalı dondurucuda $20{ }^{\circ} \mathrm{C}$ 'ye maruz kaldıktan sonra 6 saat süre ile farklı $\mathrm{pH}(2.0,7.0$ ve 12.0) çözeltilerine daldırılmıştır. $\mathrm{Bu}$ işlem bir döngü olarak kabul edilmiş ve her 5 döngüde bir doğal taşların fiziko-mekanik özellikleri tayin edilip 20 döngü sonunda döngüsel işlem tamamlanmıştır (Sarıcı ve Özdemir, 2018).

\subsubsection{Schmidt Çekici Sertlik}

Numune üzerine uyguladıkları darbe enerjilerine göre L ve N tip Schmidt çekici olmak üzere ikiye ayrılmaktadır. L tipi Schmidt çekiçlerinin uyguladı $\breve{g}_{1}$ darbe enerjisi $0,735 \mathrm{Nm}$ iken $\mathrm{N}$ tiplerinde bu değer 2,207 Nm'dir. Fakat laboratuvar ortamında karot numuneleri üzerinde yapılan sertlik deneylerinde $\mathrm{N}$ tipi çekiç yerine L tipi çekiç tercih edilmelidir. Bu çalışmada, L tipi Schmidt çekici kullanılarak ve ISRM (1978a) tarafından önerilen yöntem kullanılarak tayin edilmiştir. $\mathrm{Bu}$ yönteme göre her bir numune üzerinde 20 ölçüm alınmış ve en büyük 10 değerin aritmetik ortalaması belirlenmiştir.

\subsubsection{Ultrasonik Dalga Hızı}

Maden, inşaat, jeoloji gibi yer bilimleri çalışmalarında, ultrasonik dalga hızı kayaç veya betonun dinamik özelliklerini (poisson oranı ve elastisite modülü) dolaylı olarak tayin edilmesinde kullanılan en yaygın test yöntemidir. Yöntemin en büyük avantajları, hızlı, kolay ve hem arazi hem de laboratuvar koşullarında uygulanabilir olmasıdır. $\mathrm{Bu}$ çalışmada, farklı çözeltilere maruz kalan kayaçların P dalga hızlarındaki değişimler ISRM 1978b'de önerilen standarda göre tayin edilmiştir.

\subsubsection{Tek Eksenli Basınç Dayanımı}

Tek eksenli basınç dayanımı, belirli bir geometriye sahip (silindirik, kübik) kayaca herhangi bir yanal basınç etki etmeksizin düşey yönde etki eden kuvvete karşı gösterdiği maksimum direnç olarak ifade edilmektedir. $\mathrm{Bu}$ değer, maden, inşaat, jeoloji, jeofizik mühendisliğine ait yapı ve tasarım çalışmalarında kullanılan önemli parametredir. $\mathrm{Bu}$ çalışmada, farklı çözeltilere maruz kalan kayaçların tek eksenli basınç dayanım değerleri ISRM 1978c'de önerilen standarda göre tayin edilmiştir.

\section{Araştırma Sonuçları ve Tartışma}

Deneysel çalışmalarda kullanılan travertenlerin XRD analiz sonuçları Tablo 1'de ve XRF analiz sonuçları Tablo 2'de verilmiştir. Ayrıca her beş döngü sonunda elde edilen Schmidt çekici sertliği, P dalga hızı ve tek eksenli basınç dayanım değerlerine ait ortalama değerler Tablo 3'de verilmiştir. Travertenlerin farklı $\mathrm{pH}(2.0,7.0$ ve 12.0) çözeltilerine ek olarak donma çözülme döngü sayısına bağlı fiziko-mekanik özelliklerindeki değişimler Şekil 2-4'de verilmiştir.

Tablo 1. Travertenlerin XRD analiz sonuçları

\begin{tabular}{cc}
\hline Örnek & Ana bileşen \\
\hline Malatya Traverten & Kalsit \\
Erzurum Traverten & Kalsit \\
\hline
\end{tabular}

Tablo 2. Travertenlerin XRF analiz sonuçları

\begin{tabular}{ccc}
\hline Örnek & $\begin{array}{c}\text { Malatya Traverten } \\
(\%)\end{array}$ & $\begin{array}{c}\text { Erzurum } \\
\text { Traverten (\%) }\end{array}$ \\
\hline $\mathrm{Fe}_{2} \mathrm{O}_{3}$ & 1.05 & 0.06 \\
$\mathrm{MgO}$ & 0.02 & 0.45 \\
$\mathrm{Al}_{2} \mathrm{O}_{3}$ & 2.17 & 0.04 \\
$\mathrm{SiO}_{2}$ & $<0.01$ & $<0.01$ \\
$\mathrm{P}_{2} \mathrm{O}_{5}$ & $<0.01$ & $<0.01$ \\
$\mathrm{~K}_{2} \mathrm{O}$ & $<0.01$ & $<0.01$ \\
$\mathrm{CaO}$ & 54.56 & 59.13 \\
$\mathrm{ZnO}$ & $<0.01$ & $<0.01$ \\
$\mathrm{SrO}$ & $<0.01$ & 0.02 \\
$\mathrm{PbO}$ & 0.01 & $<0.01$ \\
$\mathrm{Na}$ & 1.30 & 2.20 \\
Kızdırma Kaybı & 42.90 & 40.13 \\
\hline
\end{tabular}

Tablo 3. Travertenlerin döngü sayısna bağll ortalama değerleri

\begin{tabular}{|c|c|c|c|c|c|c|c|c|c|c|}
\hline \multirow[t]{3}{*}{$\begin{array}{c}\text { Kayaç } \\
\text { Ad1 }\end{array}$} & \multirow[t]{2}{*}{$\begin{array}{l}\text { Döngü } \\
\text { Sayıs1 }\end{array}$} & \multicolumn{3}{|c|}{$\begin{array}{l}\text { Tek eksenli basınç } \\
\text { dayanımı (MPa) }\end{array}$} & \multicolumn{3}{|c|}{ P dalga hızı (m/sn) } & \multicolumn{3}{|c|}{ Schmidt çekici sertliği } \\
\hline & & $\mathrm{pH}: 2$ & $\mathrm{pH}: 7$ & $\mathrm{pH}: 12$ & $\mathrm{pH}: 2$ & $\mathrm{pH}: 7$ & $\mathrm{pH}: 12$ & $\mathrm{pH}: 2$ & $\mathrm{pH}: 7$ & $\mathrm{pH}: 12$ \\
\hline & 0 & 37.12 & 37.12 & 37.12 & 3750 & 3750 & 3750 & 33.7 & 33.7 & 33.7 \\
\hline \multirow{5}{*}{ 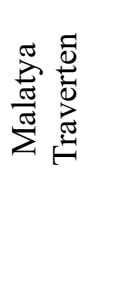 } & 5 & 35.01 & 35.50 & 35.28 & 3540 & 3615 & 3600 & 32.0 & 32.1 & 32.0 \\
\hline & 10 & 30.18 & 32.49 & 32.07 & 3112 & 3380 & 3317 & 29.2 & 30.8 & 30.1 \\
\hline & 15 & 26.30 & 30.17 & 29.07 & 2898 & 3210 & 3104 & 27.8 & 29.5 & 28.8 \\
\hline & 20 & 22.48 & 29.30 & 28.25 & 2610 & 3080 & 3010 & 26.4 & 28.9 & 28.1 \\
\hline & 0 & 44.18 & 44.18 & 44.18 & 4508 & 4508 & 4508 & 35.6 & 35.6 & 35.6 \\
\hline \multirow{4}{*}{ 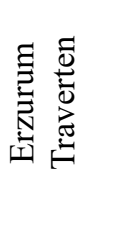 } & 5 & 41.85 & 43.74 & 42.47 & 4274 & 4324 & 4350 & 34.8 & 35.0 & 34.9 \\
\hline & 10 & 37.72 & 40.78 & 38.95 & 4012 & 4180 & 4204 & 33.0 & 34.0 & 33.2 \\
\hline & 15 & 34.99 & 39.41 & 36.17 & 3804 & 4002 & 3980 & 31.0 & 32.3 & 31.7 \\
\hline & 20 & 32.70 & 38.19 & 35.46 & 3452 & 3842 & 3801 & 29.1 & 30.9 & 30.1 \\
\hline
\end{tabular}




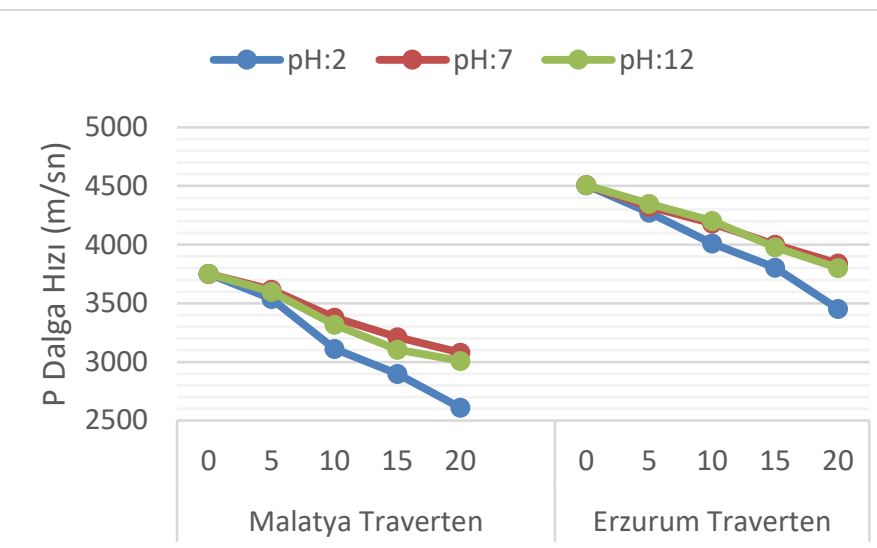

Döngü Sayısı

Şekil 2. Farklı pH çözeltileri ve donma çözülmenin P dalga hızına birlikte etkisi

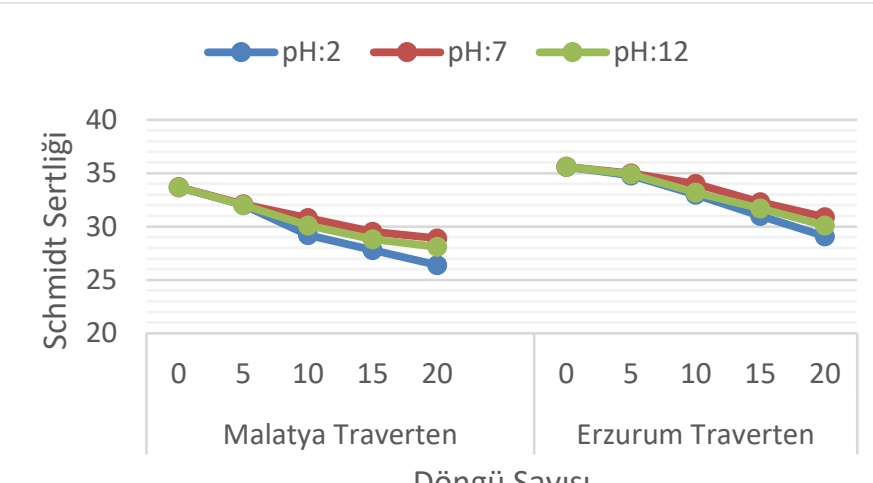

Döngü Sayısı

Şekil 3. Farklı pH çözeltileri ve donma çözülmenin Schmidt sertliğine birlikte etkisi

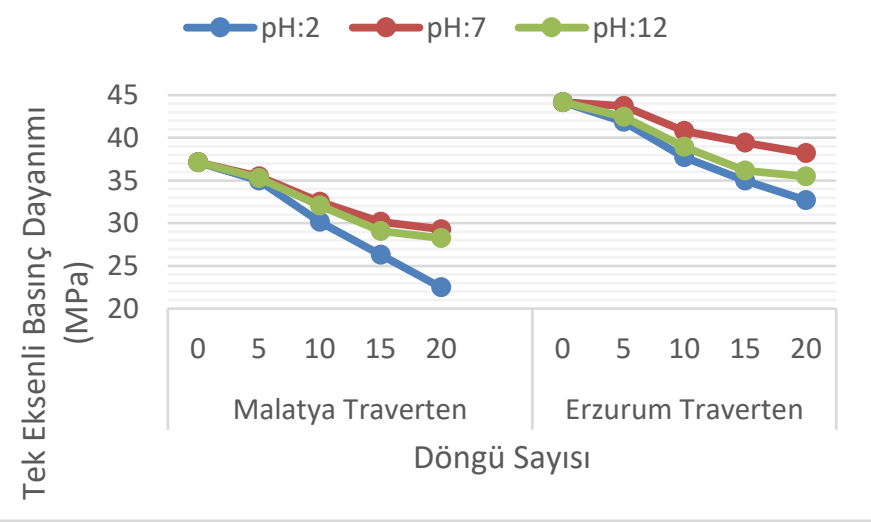

Şekil 4. Farklı pH çözeltileri ve donma çözülmenin tek eksenli basınç dayanımına birlikte etkisi

Donma çözülme döngülerinin her iki kayaç içinde fizikomekanik özelliklerine olumsuz etkileri olduğu Şekil 2-4'te verilmiştir. Şekil 2 incelendiğinde döngü sayısındaki artışa bağlı olarak P dalga hızlarında azalmalar söz konusudur. Bunun ana nedeni, suyun gözeneklere girmesi ve mevcut hacminin \%9'u kadar ekstradan hacim kaplamasına bağlı olarak, kayaçların bünyesine uyguladıkları gerilmelerden kaynaklı yeni gelişen gözeneklerdir. Bilindiği üzere dalga boşlukta dağılım sergiler ve bu durum dalganın daha geç iletilmesine neden olmaktadır. Malatya traverten örneği, 20 donma çözülme döngü sonunda $\mathrm{pH}$ 2 çözeltisine maruziyetinde \%30.40, pH 7'de \%21.06 ve pH 12'de ise \%23.85 dalga hızı kaybı sergilemiştir. Erzurum traverten örneği ise pH 2 iken \%23.42, pH 7'de \%14.77 ve pH 12'de ise $\% 15.68$ oranlarında yüzdesel azalmalar elde edilmiştir. Momeni vd. (2015), benzer olarak donma çözülme döngü sayısındaki artışın P dalga hızında azalmaya neden olduğunu ve bu dalga hızı değerinin döngüsel donma-çözülme hasarını gösteren en iyi mühendislik (fiziko-mekanik) parametresi olarak önermişlerdir. Ayrıca asidik suyun bu gözenek artışında daha etkili olduğu da görülmektedir. Bazik ortamda her ne kadar azalma gözlemlenmiş olsa da asit kadar etkili olmadığı, bunun nedeninin ise kayacın bünyesinde tuz kristalleşmesi geçirmiş olabileceği düşünülmektedir. Graue vd., (2011), travertenlerin diğer doğal taşlara nazaran porozitelerinin yüksek olduğunu ve buna bağlı olarak ağırlıkça-hacimce su emmeye ek olarak kılcal su emme miktarlarında fazla olduğunu belirtmişlerdir. Farklı pH deney sıvıları ile yaptığı çalışmalarda, kılcal su emme katsayılılarının $\mathrm{pH}$ değeri 2 iken $0.66-4.31, \mathrm{pH} 7$ 'de $0,37-3,59$ ve $\mathrm{pH} 12$ 'de ise $0,46-3,80$ (gr. $\sqrt{ } \mathrm{sn}) / \mathrm{m} 2$ aralığında değișim gösterdiğini ifade etmişlerdir. Bundan dolayı suyun $\mathrm{pH}$ değerinin kayaçların su emme miktarlarında etkili olduğunu vurgulamıştır. Travertenlerin donma-çözülme döngü sayılarının artışı her iki travertenin Schmidt çekici sertliği değerlerinde azalmaya neden olmuştur. Ayrıca, çözeltinin $\mathrm{pH}$ değerinin azalması yani asidik değerinin artışına bağlı olarak travertenlerin Schmidt çekici sertliğindeki azalmalar olduğu Şekil 3'de görülmektedir. Bunun ana nedeni, asidin karbonat içerikli olan travertenlere ihtiva etmesiyle gelişen kimyasal tepkimeye bağlı olarak gaz açığa çıkması ve yeni kılcal, mikro ya da makro yapılı boşlukların oluşmasıdır. Böylece çözeltinin yeni yüzey alanları bulmasına neden olmaktadır. Bu durum kayacın sertlik değerinde olumsuz etkilere neden olmuştur. Malatya traverten örneği, 20 donma çözülme döngü sonunda $\mathrm{pH}$ 2 çözeltisine maruziyetinde \%27.65, pH 7'de \%14.24 ve pH 12'de ise \%16.61 dalga hızı kaybı sergilemiştir. Erzurum traverten örneği ise pH 2 iken \%18.25, pH 7'de \%13.20 ve pH 12'de ise $\% 15.45$ oranlarında yüzdesel azalmalar elde edilmiştir. Benzer olarak, Sarıcı ve Özdemir (2018) yılında yapmış oldukları çalışmada donma çözülme döngü sayıları arttıkça doğal taşların Schmidt çekici sertlik değerlerinde azalmalar olduğunu ifade etmişlerdir. Travertenlerin tek eksenli basınç dayanımları incelendiğinde hem donma çözülme döngü sayısındaki artış hem $\mathrm{de} \mathrm{Ph}$ değerlerindeki değişimlerin dayanım değerlerini etkilediği görülmektedir. Malatya traverten örneği, 20 donma çözülme döngü sonunda pH 2 çözeltisine maruziyetinde \%39.43, pH 7'de $\% 21.06$ ve $\mathrm{pH} 12$ 'de ise \%23.89 tek eksenli basınç dayanımı kaybı sergilemiştir. Erzurum traverten örneği ise pH 2 iken $\% 25.98$, pH 7'de \%13.56 ve pH 12'de ise \%19.74 oranlarında yüzdesel azalmalar elde edilmiştir. 


\section{Sonuç}

Bu çalışmada, Malatya ve Erzurum illerine ait travertenlerin donma çözülme döngülerinin ve farklı pH çözeltilerine maruziyetinin birlikte etkisi araştırılmıştır. Araştırmalar sonucunda aşağıdaki bulgular elde edilmiştir.

1- Her iki traverten örneği için donma çözülme döngü sayısındaki artış fiziko-mekanik özellikleri üzerindeki olumsuz etkiyi artmıştır.

2- Travertenler asidik ( $\mathrm{HH}: 2)$ çözeltiye maruz kaldığında diğer iki çözeltiye göre nazaran daha fazla etkilenmişlerdir. $\mathrm{Bu}$ durum asidik sıvıların yeni mikro ya da makro gözenek oluşumunda daha etkili olmasından kaynaklıdır.

3- Erzurum traverten asidik ( $\mathrm{pH}: 2)$ döngüler sonunda Schmidt sertlik değerinde $\% 18.25$, Malatya traverten ise $\% 27.65$ düşüş sergilemiştir.

4- Ultrasonik P dalga hız değerleri incelendiğinde, asidik sıvıya maruz kalan kayaçların diğer iki sıvıya nazaran az etkilendiği tespit edilmiştir. Bazik ortamdaki değişimin az alması, kayacın bünyesinde tuz kristalleşmesi geçirmiş olabileceği düşünülmektedir.

5- Her üç çözeltide kayaçların tek eksenli basınç dayanımlarında oldukça önemli dayanım kayıpları meydana gelmiştir. Malatya traverten örneğinde bu kayıp \%21.06-39.43 iken Erzurum traverten örneğinde \%13.56-25.98 aralığında düşüş elde edilmiştir.

Sonuç olarak her iki traverten donma çözülme ve farklı pH çözeltilerine maruziyeti sonrasında fiziko-mekanik özelliklerinde önemli değişimler sergilenmiştir. Ancak, asidik sıvı çözeltisine maruz kalan kayaçların daha fazla dayanım kaybı yaşadığı tespit edilmiştir. Atmosfere salınan asidik gazların yağmur, çiğ, kar, sis veya kuru parçacıklar halinde yeniden yeryüzüne ulaşması ve bunların sıv1 halinde kayacın gözeneklere sızmasından kaynaklı dayanım kayıplarının belirlenmesi yapının duraylılığı için önem arz etmektedir.

\section{Kaynakça}

Aghababaei M., Behnia M., Moradian O. (2019). Experimental investigation on strength and failure behavior of carbonate rocks under multistage triaxial compression. International Journal of Rock Mechanics and Mining Sciences, 104099.

Akin M, Ozsan A. (2011). Evaluation of the long-term durability of yellow travertine using accelerated weathering tests. Bulletin of Engineering Geology and the Environment, 70, 101-114.

Amirkiyaei,V., Ghasemi E., Faramarzi L. (2020). Determination of P-wave velocity of carbonate building stones during freeze-thaw cycles. Geotechnical and Geological Engineering, 38(6), 5999-6009.

Barone G., Mazzoleni P., Pappalardo G., Raneri S. (2015). Microtextural and microstructural influence on the changes of physical and mechanical proprieties related to salts crystallization weathering in natural building stones. The example of Sabucina stone (Sicily). Construction and Building Materials, 95, 355-365.

Deng H., Li J., Zhu M., Wang K., Wang L., Deng C. (2012). Experimental research on strength deterioration rules of sandstone under "saturation-air dry" circulation function. Rock and Soil Mechanics, 33, 3306-3312.
Erdogan O., Ozvan A. (2015). Evaluation of strength parameters and quality assessment of different lithotype levels of Edremit (Van) Travertine (Eastern Turkey), Journal of African Earth Sciences, 106, 108-118.

Fener M., Ince I. (2015). Effects of the freeze-thaw (F-T) cycle on the andesitic rocks (Sille-Konya/Turkey) used in construction building. Journal of African Earth Sciences, 109, 96-106.

Freire-Lista D.M., Fort R., Varas-Muriel M.J. (2015). Freezethaw fracturing in building granites. Cold Regions Science and Technology, 113, 40-51.

Gökçe M.V., İnce İ., Fener M, Taşkıran T., Kayabali K. (2016). The effects of freeze-thaw (F-T) cycles on the Gödene travertine used in historical structures in Konya (Turkey). Cold Regions Science and Technology, 127, 65-75.

Graue B., Siegesmund S., Middendorf B.. (2011). Quality assessment of replacement stones for the cologne cathedral: mineralogical and petrophysical requirements. Environmental Earth Science, 63, 1799-1822.

Hajpál M. (2002). Changes in sandstones of historical monuments exposed to fire or high temperature. Fire Technology, 38, 373-382.

Hale P.A., Shakoor A. (2003). A laboratory investigation of the effects of cyclic heating and cooling, wetting and drying, and freezing and thawing on the compressive strength of selected sandstones. Environmental and Engineering Geoscience, 9, 117-130.

ISRM (1978a). Suggested methods for determination of the Schmidt rebound hardness. International Journal of Rock Mechanics and Mining Sciences Geomechanics Abstracts, 15(3), 101-102.

ISRM (1978b). Suggested methods for determining sound velocity, International Journal Of Rock Mechanic and Mining Science and Geomechanic Abstract, 15, 53- 58.

ISRM (1978c). Suggested Methods For Determining The Uniaxial Compressive Strength and Deformability of Rock Materials, International Journal of Rock Mechanics and Mining Science and Geomechanical Abstract, 16, 135-140.

Jamshidi A., Nikudel M.R., Khamehchiyan M. (2016). Evaluation of the durability of Gerdoee travertine after freeze-thaw cycles in fresh water and sodium sulfate solution by decay function models. Engineering Geology, 202, 36-43.

Koca M.Y., Ozden G., Yavuz A.B., Kincal C., Onargan T., Kucuk K. (2006). Changes in the enginering properties of marble in fire-exposed columns. International Journal of Rock Mechanics and Mining Science and Geomechanical Abstract, 43, 520-530.

Kryza R., Prell M., Czechowski F., Domaradzka M. (2009). Acidic weathering of carbonate building stones: experimental assessment (preliminary results). Studia Universitatis BabeşBolyai. Geologia, 54, 33-36.

Lam dos Santos J.P., Rosa L.G., Amaral P.M. (2011). Temperature effects on mechanical behavior of engineered stones. Construction and Building Materials, 25, 171-174.

Luo X., Zhou S., Huang B., et al. (2021). Effect of freeze-thaw temperature and number of cycles on the physical and mechanical properties of marble. Geotechnical and Geological Engineering, 39, 567-582.

Momeni A., Abdilor Y., Khanlari G.R. et al. (2016). The effect of freeze-thaw cycles on physical and mechanical properties of granitoid hard rocks. Bulletin of Engineering Geology and the Environment, 75, 1649-1656. 
Müller U. (2008). The mineralogical composition of sandstone and its effect on sulphur dioxide deposition. Materiales de Construcción, 58, 81-95.

Oguchi C.T., Yuasa H. (2010). Simultaneous wetting/drying, freeze/thaw and salt crystallization experiments of three types of Oya tuff. Geological Society, London, Special Publications, 333, 59-72.

Ozguven A., Ozcelik Y. (2014). Effects of high temperature on physico-mechanical properties of Turkish natural building stones. Engineering Geology, 183, 127-136.

Sarıcı D.E., Kızılkaya N., Özdemir E., Polat F. (2018). Evalution of salt crystallisation effects on artificial marble. Journal of Physical Chemistry and Functional Materials, 1(2), 20-24.

Sarici D.E., Ozdemir E. (2018). Determining point load strength loss from porosity, Schmidt hardness, and weight of some sedimentary rocks under freeze-thaw conditions. Environmental Earth Sciences, 77, 62.

Sharma P.K., Khandelwal M., Singh T.N. (2007). Variation on physico-mechanical properties of Kota stone under different watery environments. Building and Environment, 42, 41174123.

Swathy M., Karpagam B., Manu S., Arun M. (2020). Characteristics and deterioration mechanisms in coral stones used in a historical monument in a saline environment. Construction and Building Materials, 241, 118102.

Taghipour M., Nikudel M.R., Farhadian M.B. (2015). Engineering properties and durability of limestones used in Persepolis complex, Iran, against acid solutions. Bulletin of Engineering Geology and the Environment, 1-12.

Vincenzo F., Antonio F., Michele L., Maria N.M., Luigi S. (2018). Petrographic features influencing basic geotechnical parameters of carbonate soft rocks from Apulia (southern Italy). Engineering Geology, 233, 76-97.

Weddfelt K., Saadati M., Larsson P.L. (2017). On the load capacity and fracture mechanism of hard rocks at indentation loading. International Journal of Rock Mechanics and Mining Sciences, 100, 170-176.

Yavuz A.B., Topal T. (2007). Thermal and salt crystallization effects on marble deterioration: examples from Western Anatolia, Turkey. Engineering Geology, 90(1-2), 30-40. 